\title{
Comparison of the effects of a liquid yogurt and chocolate bars on satiety: a multidimensional approach
}

\author{
Didier Chapelot ${ }^{1 *}$ and Flore Payen ${ }^{2}$ \\ ${ }^{1}$ Laboratoire des Réponses Cellulaires et Fonctionnelles à l'Hypoxie, Université Paris 13, UFR SMBH, 74 rue Marcel Cachin, \\ 93017 Bobigny, France \\ ${ }^{2}$ Yoplait France, Service Nutrition, 150 rue Galliéni, 92641 Boulogne Cedex, France
}

(Received 31 March 2009 - Revised 24 August 2009 - Accepted 1 September 2009 - First published online 29 October 2009)

In the context of epidemic obesity, satiety is an important target for nutritional interventions. Using a multidimensional approach, we compared the effect on satiety of two food products frequently consumed in France by young adults as a small mid-afternoon meal called the 'goûter'. Participants were eighteen healthy young males (aged 20.8 (SD 1.8) years) of normal body weight (BMI 21.7 (SD 1.7 ) $\mathrm{kg} / \mathrm{m}^{2}$ ) used to eating four times per d including a 'goûter'. On two occasions, under laboratory conditions, the time-blinded participants consumed a fixed energy lunch $(2.8 \mathrm{MJ})$ and, $240 \mathrm{~min}$ later, either a liquid yogurt or chocolate bars matched for energy (1.2 MJ) and weight $(366 \mathrm{~g})$. Then, satiety was assessed by: (1) ratings of hunger, appetite, desire to eat and fullness at 20 min intervals (perception), (2) the delay until the subject requested his dinner meal (duration) and (3) energy intake at this meal (consumption). Results showed that satiety was perceived higher after liquid yogurt than chocolate bars over the $60 \mathrm{~min}$ preceding the next meal, as evidenced by hunger $(P<0.005)$, appetite, $(P<0 \cdot 005)$, desire to eat $(P<0 \cdot 04)$ and fullness $(P<0.05)$ ratings. However, its duration was similar between liquid yogurt and chocolate bars (165 (SE 8) and 174 (SE 7) min respectively) and this difference was not followed by reduced intake at dinner. In conclusion, this approach of satiety revealed that a liquid yogurt induced a lower subjective motivation to eat than chocolate bars during the hour preceding the spontaneous onset of a meal, without affecting subsequent food intake.

Satiety: Energy intake: Appetite: Liquid yogurt: Chocolate bars

Overweight and obesity are the consequences of a positive energy balance and therefore weight reduction requires that energy expenditure is increased and/or energy intake is decreased. In this perspective, increasing satiety, the term that refers to a low motivation to eat, is an important target for nutritional intervention. The effect of foods or ingredients on satiety has stimulated an abundant scientific literature in recent years. Usually, the objective is to identify the optimal diet for sustaining the highest level of satiety over the day, expecting a consistent reduction in intake. The problem is that satiety is multidimensional and consists mainly in a perception, a duration and a consumption dimension ${ }^{(1)}$. Perception is usually assessed by ratings obtained at regular intervals after eating; duration is measured as the delay until the next meal is requested and consumption as the energy intake at the next meal. Most studies on satiety conducted in human subjects using the classic preload paradigm ${ }^{(2)}$ actually disregard its duration. This raises concern, since in various species it has been shown that the duration of satiety is the main response to changes in diet composition ${ }^{(3-5)}$, cost of procurement $^{(6,7)}$ or hormones such as leptin ${ }^{(8)}$. Moreover, in humans, the duration is very sensitive to alterations in food composition or metabolic pathways ${ }^{(9-12)}$. Thus, measuring the duration of satiety is beginning to be considered as a key outcome ${ }^{(13)}$. This is all the more important since an effect on satiety perception but none on later energy intake is often reported ${ }^{(13-19)}$ and leads to difficulties in the interpretation of results.

Among the factors contributing to satiety, macronutrient composition and physical state exert a major influence. Most studies comparing proteins, fats and carbohydrates showed that, for the same energy content, satiety is highest after high-protein meals or preloads ${ }^{(20)}$. Thus, for a given eating occasion, high-protein foods appear to be more satiating than high-carbohydrate or high-fat foods, although this remains to be demonstrated with commercially available food items. Comparing the satiety provided by liquid and solid forms of energy sources has led to discrepant results. According to studies, liquids are more ${ }^{(2,21,22)}$, less ${ }^{(23-29)}$ or not differently ${ }^{(28,30,31)}$ satiating than solids. Procedures, testfoods and subjects greatly varied across studies, which may explain these discrepancies. Interestingly, fruit yogurts in liquid (drinkable) or semi-solid (eaten with a spoon) forms were followed by higher satiety ratings than solids ${ }^{(13)}$.

The aim of the present study was therefore to compare the satiating power of a liquid yogurt and chocolate bars eaten

Abbreviation: VAS, visual analogue scale.

* Corresponding author: Dr Didier Chapelot, fax +3314838 88 64, email comp-alim@smbh.univ-paris13.fr 
during the afternoon. These foods were chosen because in France, young adults often consume either of them as a small mid-afternoon meal called the 'goûter' and results may therefore be interesting to recommend a better choice in terms of satiety between these two products. The second objective was to assess if a multidimensional approach may reveal some specific differences in the satiety power of these two commercial items.

\section{Methods}

\section{Subjects}

Overall, forty-eight young male subjects aged 18-25 years were selected in the area of Grenoble through local advertisement. Overweight or obese individuals, smokers, trained athletes, individuals with food allergies or aversions to the foods provided during the experiment, with any personal or family history of diabetes or other metabolic disease, using medication or who had a change in body weight $>2 \mathrm{~kg}$ during the previous 2 months were excluded. Other main exclusion criteria were based on eating behaviour parameters: scores $>9$ on the F1-restrained eating score of the Three Factor Eating Questionnaire ${ }^{(32)}$, or eating at irregular hours. Another inclusion criterion was eating a 'goûter' since childhood, at least $5 \mathrm{~d}$ per week, bringing $>0.9 \mathrm{MJ}$. Last, subjects had to be familiar with both test foods. Among the selected subjects, twenty fulfilled all these criteria and were included and randomised, but two subjects were withdrawn because they did not attend both test sessions. Based on previous calculations $^{(33)}$, using a repeated-measures design and a study power of 0.8 , a $5 \mathrm{~mm}$ difference on mean $4.5 \mathrm{~h}$ ratings can be detected with eighteen subjects. Moreover, in our previous studies, differences in intake and in duration of satiety were found with twelve $\mathrm{e}^{(34)}$ and eight ${ }^{(9)}$ subjects, respectively. Thus, our sample was considered powerful enough for our objectives. Characteristics of the participants are shown in Table 1. The present study was conducted according to the guidelines laid down in the Declaration of Helsinki and was approved by the local ethics committee (Comité de Protection des Personnes Sud Est III) and the Health Authorities (Direction Générale de la Santé). Written informed consent was obtained from all subjects. Subjects were told that the present study would evaluate various parameters of eating behaviour in relation to different types of foods.

Table 1. Participants' characteristics

(Mean values and standard deviations for eighteen subjects)

\begin{tabular}{lrr}
\hline & Mean & SD \\
\hline Age (years) & $20 \cdot 8$ & $1 \cdot 8$ \\
Body weight (kg) & $70 \cdot 8$ & $8 \cdot 8$ \\
Height (cm) & $180 \cdot 4$ & 6.7 \\
BMI (kg/m²) & $21 \cdot 7$ & $1 \cdot 7$ \\
Three Factor Eating Questionnaire & & \\
$\quad$ Restrained eating score (F1) & $2 \cdot 7$ & $1 \cdot 3$ \\
Disinhibition score (F2) & 4.5 & $2 \cdot 6$ \\
$\quad$ Hunger score (F3) & $5 \cdot 0$ & 3.5 \\
Frequency of 'goûter' (number/week) & $5 \cdot 6$ & $1 \cdot 1$ \\
Energy intake at the 'goûter' (MJ)* & 1.5 & 0.5 \\
\hline
\end{tabular}

* 'Goûter' is a French word to describe a small mid-afternoon meal.

\section{Study design}

The present study had a randomised cross-over design. Two test sessions took place under laboratory settings, separated by a washout period of at least $6 \mathrm{~d}$.

\section{Foods}

In the present study, we chose to use a preload procedure with a fixed energy intake at lunch, because it was closest to the eating habits of our subjects, mostly students who usually ate in a cafeteria serving fixed amounts of foods. We therefore decided to simulate this naturalistic condition by serving a traditional meal of similar energy content and food choices as usually served in these restaurants.

During a pre-experimental session, subjects rated the pleasure provided by each food that would be served during the sessions on three category ratings (negative, neutral, positive).

Lunch consisted of a traditional meal with vegetables (mixed), meat (roast beef), French beans, bread, butter, dairy dessert and apple sauce $(685 \mathrm{~g}, 2800 \mathrm{~kJ}$ with $27.6 \%$ protein, $31.6 \%$ fat and $40.8 \%$ carbohydrate).

The 'goûter' consisted of either a strawberry-flavoured liquid yogurt commercialised under the name of Yop ${ }^{\circledR}$ (Yoplait Co., Boulogne-Billancourt, France) or a popular chocolate bar (Twix; Mars Inc., McLean, VA, USA). Ratings of palatability scales in the pre-experimental session showed that subjects appreciated both products similarly. To improve the relevance of the experiment to naturalistic conditions, the quantity provided to subjects was based on the usual individual portions of the commercially available chocolate bars, i.e. two bars $(58 \mathrm{~g} ; 1190 \mathrm{~kJ})$. Water was ingested with the chocolate bar in order to equate the volume of liquid yogurt to match the energy content in the chocolate bar condition $(308 \mathrm{ml})$. Thus, both products were matched for energy, volume and density (see Table 2). An unpublished study conducted by the manufacturer has shown that consumers do not drink water or soda with this liquid yogurt in naturalistic conditions (Yoplait Co., unpublished results). Thus, no beverage was considered necessary with the liquid yogurt.

Since our dinner test meal was designed to measure energy intake and not food selection, it was not a buffet-type. Moreover, in previous studies ${ }^{(35-37)}$, we observed that most of the modifications in intake concern the first or the main course of a meal. Therefore, dinner consisted of one main course composed of pasta, meat and tomato sauce and known as Bolognese lasagne $(588 \mathrm{~kJ} / 100 \mathrm{~g}$ with $13.3 \mathrm{~g}$ carbohydrate (38\% energy), $6.2 \mathrm{~g}$ fat (40\% energy) and $7.9 \mathrm{~g}$ protein $(22 \%$ energy)). A semi-solid fruit yogurt was served as dessert in its usual commercial size $(125 \mathrm{~g})$. It could be eaten only partially, or another one could be requested. The main course was served on an individual tray in a large portion of $600 \mathrm{~g}$. The portion represented $3525 \mathrm{~kJ}$ and was twofold the commercial single portion. Participants were instructed to eat until they felt comfortably full, and the same amount was provided again if more was asked for.

\section{Satiety evaluation}

The perceived satiety was assessed using hunger, appetite, desire to eat, and fullness ratings on visual analogue scales (VAS). 
Table 2. Composition of the products

\begin{tabular}{lcc}
\hline & Liquid yogurt & Chocolate bars \\
\hline Portion & 366 & 58 \\
$\quad$ Product (g) & - & 308 \\
$\quad$ Water (ml) & 1.2 & \\
Energy & 3.3 & 1.2 \\
$\quad$ Per portion (MJ) & 10.2 & 3.3 \\
$\quad$ Density (kJ/g) & 16.0 & 2.7 \\
Protein & & 5.0 \\
$\quad$ Per portion (g) & 4.7 & 13.7 \\
$\quad$ Percentage of energy (\%) & 7.3 & 25.3 \\
Fat (g) & & 37.8 \\
$\quad$ Per portion (g) & 49.0 & 69.7 \\
$\quad$ Percentage of energy (\%) & 76.7 & \\
$\quad$ Per portion (g) & & \\
$\quad$ Percentage of energy (\%) & &
\end{tabular}

Each VAS was presented on a separate sheet and consisted of a $100 \mathrm{~mm}$ horizontal line, anchored at the left end with 'not at all' and the right end 'extremely'. Phrases were 'Do you feel hungry' for the hunger scale, 'How is your appetite?' for the appetite scale, 'Do you desire to eat something you like very much?' for the desire to eat scale, and 'How full do you feel your stomach is?' for the gastric fullness scale.

Duration was assessed as the delay between the start of the 'goûter' and the request for the dinner meal. As in previous studies $^{(35-37)}$, participants were encouraged to ask for their dinner when they perceived a hunger signal.

Intake was assessed as the difference between the weight of food served at dinner and leftovers. Energy intake was calculated by multiplying this difference by the energy value of each item as provided by food tables from the CIQUAL (Agence Française de Sécurité Sanitaire des Aliments) or by the manufacturer when necessary.

\section{Study protocol}

For the $48 \mathrm{~h}$ preceding each session day, subjects were requested to maintain their usual dietary and occupational habits and to avoid any excessive consumption of food. On the previous evening they had their dinner at home, and were required to limit consumption of poorly digestible foods such as highfibre items (a list was provided). They were asked to have strictly identical dinners (i.e. amount and composition) on both days preceding the test sessions. Food ingestion was forbidden after 20.30 hours and only water was allowed. On the morning of the test sessions, participants consumed their usual breakfast at home. Its composition had also to be strictly identical before each session. Participants arrived at the investigation centre at 11.00 hours. Their dinner on the previous day and breakfast intakes were checked with the investigator by asking participants about the precision of their reports. They were then isolated in single rooms and deprived of time cues by removing watches, phones, and covering windows with black curtains. The standard lunch was served between 12.15 and 13.15 hours according to the eating habits of the subject, at the same time for both sessions. The 'goûter' was served $240 \mathrm{~min}$ after the start of lunch. It had to be consumed in less than $15 \mathrm{~min}$. VAS were rated before, immediately after and then every 20 min until dinner was requested. Dinner was served in each participant's individual room. Participants were informed that they would have to stay at the investigation centre until 22.00 hours to prevent any premature request. After 22.00 hours, they were free to leave the laboratory unit.

\section{Data analysis}

All results are presented as mean values with their standard errors except otherwise indicated. Statistical analyses were performed using Systat software (version 10.2; SPSS, Chicago, IL, USA). VAS scores were subjected to a stepwise analysis for serial measurements according to Matthews et al. ${ }^{(38)}$. Thus, for each rating (hunger, appetite, desire to eat and fullness), three variables of interest were determined: (1) a post-'goûter' profile from the start of the 'goûter' to the time when the earliest dinner was requested across all conditions and participants; (2) a pre-dinner profile starting from $60 \mathrm{~min}$ before the dinner request until dinner request; (3) a profile in percentages with each individual intermeal interval transformed in quartiles ${ }^{(39)}$. The first variable assessed the time course of the scores during a fixed time period including all participants and conditions. The second variable assessed satiety during the period preceding the meal as it is usually done in studies using duration of satiety ${ }^{(10,11,40,41)}$. The third variable allowed proceeding to statistics on the complete interval between meals including all subjects. However, the different number of ratings in each quartile across subjects led us to treat the results with caution. A global satiety score was also calculated, adapted from the model of Holt et al. ${ }^{(42)}$, as the sum of the four ratings representing satiety: fullness score $+(100-$ hunger score $)+(100-$ appetite score $)$ $+(100-$ desire to eat score $)$. The objective was to determine whether the global satiety state when participants asked for their dinner meal was different according to the product consumed for 'goûter'.

For temporal data, ANOVA with repeated measures was conducted with time and conditions (liquid yogurt and chocolate bars) as within-subject factors, and order of the sessions as the between-subject factor. When an interaction between time and conditions was found, the post- and pre-dinner profiles were analysed using paired Student's $t$ tests or the Wilcoxon test, depending on the normality of the distribution, corrected for the number of tests according to Bonferroni. The normality of the distribution was tested by a Shapiro-Wilk's test.

The values in each quartile of the intermeal interval in percentages, the delay of the dinner request and energy intake at dinner were compared between conditions using paired Student's $t$ tests. Relationships between satiety dimensions were calculated using Pearson correlations for all subjects and all conditions. A $P$ value $<0.05$ was considered statistically significant.

\section{Results}

\section{Duration}

Dinner was requested within 165 (SE 8) min after the 'goûter' in the liquid yogurt condition (range 90-216 min) and within 174 (SE 7) $\mathrm{min}$ in the chocolate bar condition (range $130-240 \mathrm{~min}$ ). This duration of satiety was not significantly different between the conditions. 

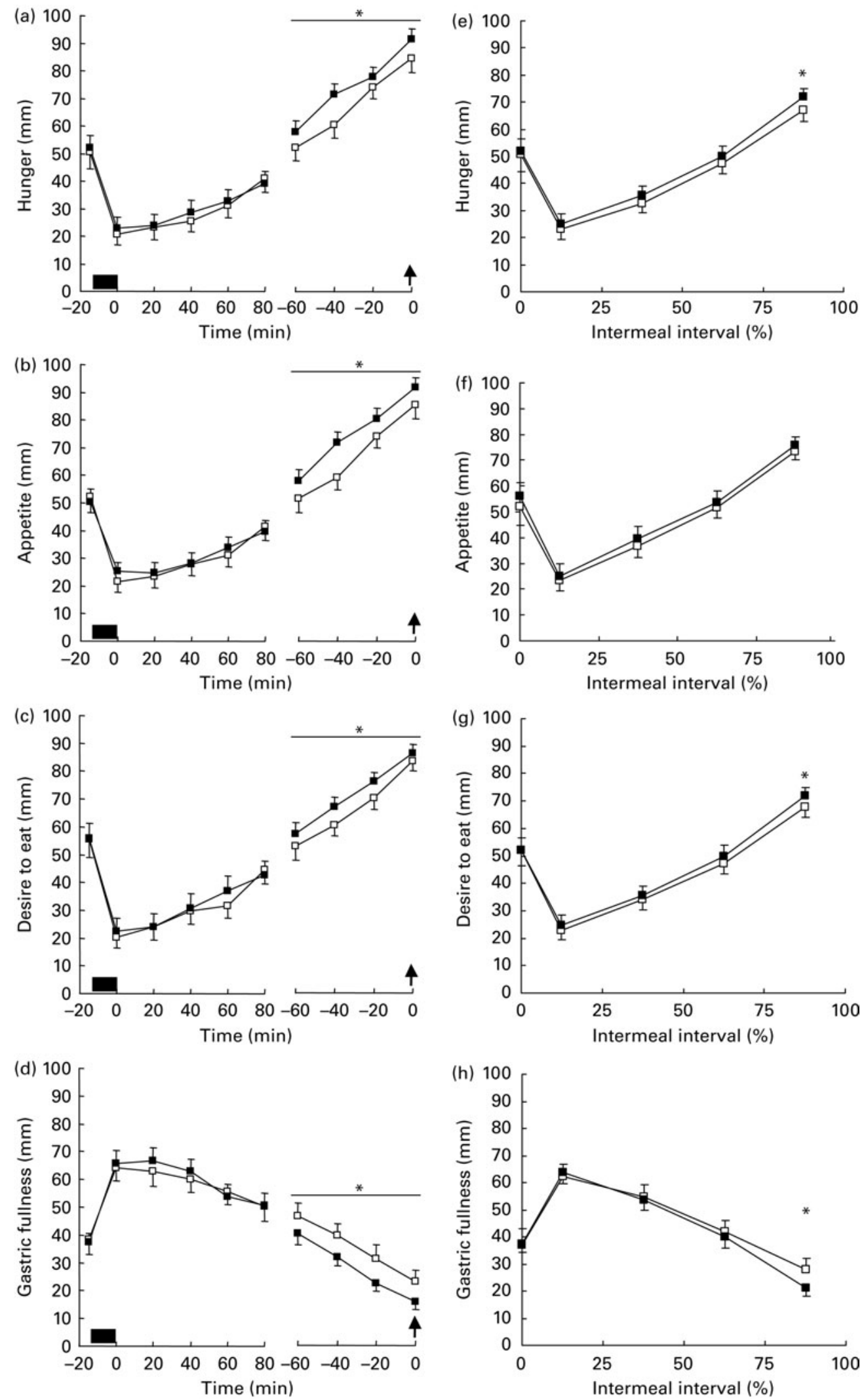

Fig. 1. Perception dimension of satiety. Hunger (a), appetite (b), desire to eat (c) and gastric fullness (d) ratings on the visual analogue scales (VAS) until the first subject asked for his dinner ( -20 to $80 \mathrm{~min}$ on the $x$-axis) and during the hour preceding the dinner request ( -60 to 0 min on the $x$-axis) after the liquid yogurt ( $\square$ ) and chocolate bars $(\boldsymbol{\square})$. Hunger (e), appetite $(\mathrm{f})$, desire to eat $(\mathrm{g})$ and gastric fullness (h) ratings on the VAS with intermeal interval in percentages of interval (quartiles). Values are means, with standard errors represented by vertical bars. ${ }^{*}$ Mean value was significantly different from that of the liquid yogurt condition $(P<0.05)$. —, Goûter intake; $\uparrow$, dinner request. 


\section{Perception}

Hunger, appetite, desire to eat and fullness ratings at the time of the 'goûter' were not different between the conditions. Since the earliest dinner request among subjects and conditions occurred $80 \mathrm{~min}$ after the 'goûter' and VAS were rated every $20 \mathrm{~min}$, the post-'goûter' profile was calculated on four time-points. A time effect appeared $(P<0 \cdot 001)$ but no condition effect nor interaction between time and condition was found for hunger, appetite, desire to eat or fullness ratings.

For the pre-dinner profiles, a time effect and a condition effect for hunger, appetite, desire to eat and fullness ratings appeared $(P<0.05)$, without interaction between time and condition. Thus, compared with the chocolate bar condition, hunger $(P<0 \cdot 005)$, appetite $(P<0.005)$ and desire to eat $(P<0.04)$ ratings were lower and gastric fullness higher $(P<0.05)$ during the pre-dinner period in the liquid yogurt condition (Fig. 1).

When analysed in quartiles, hunger and desire to eat ratings during the last quartile of the intermeal interval were lower ( $P=0.005$ and $P<0 \cdot 05$, respectively) and gastric fullness ratings higher $(P<0.05)$ in the liquid yogurt than in the chocolate bar condition.

Furthermore, dinner was requested with a higher global satiety score in the liquid yogurt than in the chocolate bar condition (17.3 (SE 4.0) v. 12.9 (SE 2.6) $\mathrm{mm} ; P<0.05)$.

\section{Consumption}

Total energy intake at dinner was 4677 (SE 171) and 4761 (SE 226) $\mathrm{kJ}$ in the liquid yogurt and chocolate bar conditions, respectively (NS). Intake of lasagne, bread and fruit yogurt was not different according to condition, as was water intake (Fig. 2). Among the thirty-six dinner occasions, two subjects asked at one of their dinners for another portion, and only one finished his portion. In all the other dinners, subjects left at least $50 \mathrm{~g}$ in their dish or plate.

\section{Correlations}

The difference in the duration of satiety and the difference in appetite ratings at dinner request between conditions were significantly correlated $(r \quad 0.498 ; P<0.05)$. This was not

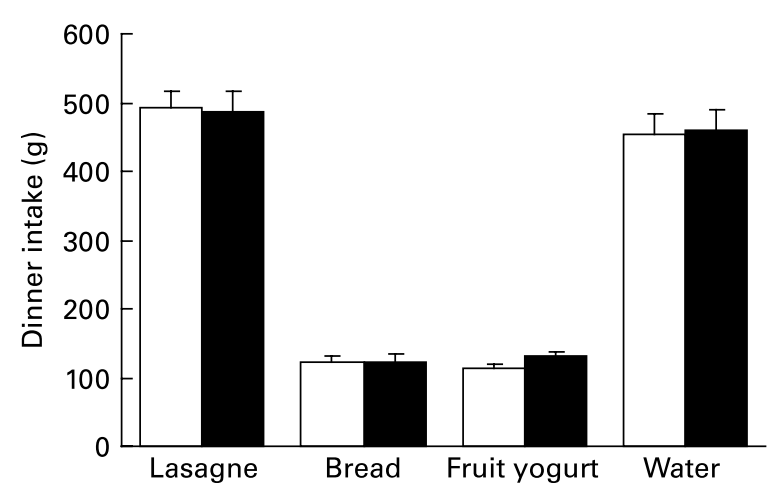

Fig. 2. Consumption dimension of satiety. Amount $(\mathrm{g})$ of lasagne, bread, yogurt and water consumed at the dinner meal in the liquid yogurt $(\square)$ and chocolate bar ( $\square$ ) conditions. For energy intake at this meal, see the Results section. Values are means, with standard errors represented by vertical bars. found with hunger, desire to eat, fullness ratings or satiety index. Thus the longer the duration of satiety, the greater was the difference in appetite rating at dinner request.

\section{Discussion}

The present study was an attempt to identify potential differences in satiating power between two food products widely consumed by adolescents and young adults in a small midafternoon meal called the 'goûter' in France. One of these foods was a liquid yogurt and the other chocolate bars. To assess satiety, three dimensions were measured: its perception, its duration, and consumption at the next meal. To measure duration, we recreated a spontaneous eating situation according to a time-blinded procedure as described by our ${ }^{(10,11,34-36,40,41)}$ and other teams ${ }^{(12,43)}$. Since the satiety power of foods eaten in a non-hungry state is weak ${ }^{(11,36,40,41)}$, we chose to select subjects usually eating a 'goûter' as done in previous studies ${ }^{(36,37)}$. Thus, only participants consuming a 'goûter' between lunch and dinner almost everyday from childhood were selected to participate in the sessions.

The first result of the present study is that the duration of post-'goûter' satiety did not differ between the test products, i.e. about $170 \mathrm{~min}$ long for both foods. A study conducted in consumers recently revealed (Yoplait Co., unpublished manufacturer's results) that most of them expected a satiety of $\leq 2 \mathrm{~h}$ after the consumption of this liquid yogurt or the chocolate bars used in the present study. This suggests that our participants requested their dinner meal according to physiological rather than cognitive factors.

Differences in satiety were found in its perception dimension. These differences were only observed during the hour preceding the dinner request and were significant for all ratings: hunger, appetite, gastric fullness and desire to eat. Each of these ratings is considered to represent a different dimension of satiety although the precise underlying physiological meaning remains unclear. VAS ratings show a good degree of reliability and validity when used in a within-subject design but must be associated with other measures of eating behaviour $^{(44)}$. Hunger ratings are supposed to represent the energy need, desire to eat ratings a wanting for a specific food, and fullness ratings are taken to reflect the digestive state of the subject. Among these ratings, fullness has shown the highest correlation with intake ${ }^{(45)}$. An 'appetite' rating was added since in France the meaning of the term does not totally overlap 'hunger' and 'desire to eat'. It was considered interesting to verify whether its variations and relationships with duration of satiety and later intake were similar to the other three scales.

Subjective hunger sensations may represent an homeostatic motivation to eat, whereas ratings of desire to eat as rated in the present study may indicate a motivation for the pleasure produced by food, in other terms, a non-homeostatic or hedonic motivation ${ }^{(46)}$. Fullness is probably the sensation of stomach distension. Appetite is usually not added to these three classic scales. Here we wanted to test our hypothesis of a distinct meaning. Although its variations were consistent with other ratings, it was the only rating obtained at the time of dinner request that correlated with the duration of satiety. If this is confirmed in the future, it may represent an interesting 
subjective tool for studying the time-induced effects on satiety.

Altogether, these ratings provide information on the level of motivation to eat, but it is not known if this may have consequences for eating behaviour in real-life conditions. For this, it would be interesting to test if ratings of satiety modulate the threshold at which subjects initiate eating in the presence of palatable food during their normal intermeal interval. This would be an important demonstration of the clinical relevance of the satiety scores usually published in support of the increased satiety power of certain foods.

A conclusion that can be drawn from the present results is that in the hour preceding the dinner meal, participants experienced a lower level of motivation to eat when the liquid yogurt was consumed in the afternoon than after the chocolate bars. This might represent a benefit for individuals who feel more vulnerable to food when dinnertime comes.

This difference in perceived satiety observed for hunger at the moment of dinner request shows that individuals can request a meal at various levels of perceived hunger. Moreover, the satiety index, a variable constructed from all four ratings and providing an insight into the motivation to eat at meal request, was higher after the liquid yogurt than after the chocolate bars.

However, these differences in satiety ratings at dinner request were not followed by a consistent difference in intake. Importantly, the amount eaten at a meal is rarely modified when the intermeal interval is free ${ }^{(10,11,17,40,41)}$. Since it has been demonstrated in animals ${ }^{(47)}$ that the duration between meals and not meal size is the adaptation mechanism of food intake, this is not surprising. When meal times are fixed, meal size becomes an important factor of energy homeostasis. Although the metabolic state at the onset of a meal might be considered a determinant of intake, inconsistency between satiety ratings and intake is frequently reported when a meal is provided at a fixed time ${ }^{(13-19)}$. This raises the problem of assessing the satiety power of food by the size of the next meal, which is determined by a satiation mechanism. Satiation is mainly driven by sensory and digestive factors and is a conditioned process based on repeated exposures to food. To expect any reduction in intake after a single consumption of a food is therefore not completely appropriate. Last, as stated by some authors ${ }^{(44)}$, “"objective food intake" may not be as objective or as "uncontaminated" an outcome as it ostensibly appears'. This makes the intake dimension of satiety difficult to interpret in short-term studies such as those generally published in this area of research. In the present study, one possible limitation is that subjects had to ask for another one portion of the main course if they finished the first one. This may have reduced the chances to see differences in intake between conditions. Moreover, they may have eaten until their portion was finished and not until they felt comfortably satiated. However, results showed that except one subject in one condition, all either left more than $50 \mathrm{~g}$, and two asked for another portion. This argues for an actual ad libitum intake and the validity of our intake results.

Explanations of the observed differences in the perception of pre-dinner satiety between these two products are only hypothetical since no biological parameters were measured. Moreover, our two products differed by several properties. Among those considered, the most likely to explain these results are the physical form (liquid for the yogurt and solid for the chocolate bars) and the protein content (high for the yogurt and low for the chocolate bars). It has been reported that a food associated with water is either less ${ }^{(48)}$ or more ${ }^{(24)}$ satiating that this food in a liquid form. Among the factors that have been proposed to explain why yogurts have a higher satiety power than drinks are their viscosity ${ }^{(29)}$ and the fact that they are consumed with a spoon ${ }^{(49)}$. However, in a recent study ${ }^{(13)}$, a liquid yogurt did not differ in satiating power from its semi-solid version eaten with a spoon. Therefore, the satiety power of yogurts is unlikely to be related to its textural properties.

According to many reports, proteins have the most potent satiety power compared with carbohydrate and fat ${ }^{(20)}$. The higher protein content of the liquid yogurt compared with chocolate bars $(10 \cdot 1$ v. $2.7 \mathrm{~g}$, respectively) may have contributed to the differences in satiety. With a difference of $12.4 \mathrm{~g}$ protein, Harper et al. ${ }^{(14)}$ also reported higher satiety ratings after chocolate milk than after a sugar-sweetened drink, although with $26 \mathrm{~g}$ protein $^{(19)}$, no difference was observed. In these studies, satiety was only followed over 30 and $50 \mathrm{~min}$, so no comparisons can be made with the present results in which differences occurred at least $110 \mathrm{~min}$ (170-60 min) after consumption. Since the satiety power of protein is primarily linked to metabolic mechanisms ${ }^{(20)}$, it is likely that it may take some time to appear and this argues for the possible involvement of the protein content in the observed effect.

Several nutritional aspects are in favour of the choice of a liquid yogurt rather than chocolate bars for the 'goûter', for example, less fat, more protein, more $\mathrm{Ca}$, lower energy density, greater volume. The present results suggest that this nutritional benefit is not associated with a lower satiety power due to its physical form, as previous comparisons between liquid (milkshake) and solid (chocolate bars) meal replacements may have suggested ${ }^{(29)}$.

In addition of the limitations cited in the previous paragraphs, it must be added that it was not possible to dissimulate the true aim of the study and this may have influenced results although no element may suggest that this would have favoured the liquid yogurt.

In conclusion, using a multidimensional approach of satiety, we found that a liquid yogurt consumed as a small mid-afternoon meal (the French 'goûter') by regular 'goûter' eaters, provided the same duration of satiety as chocolate bars matched for energy load, density and volume, but a higher perception of satiety during the hour preceding the next meal when spontaneously requested. However, in the present conditions, this difference was not associated with reduced intake at this meal. A liquid yogurt may represent a good alternative to chocolate bars as a between-meal intake for improving the satiety feeling. Further studies are needed to determine if this effect might contribute to reduce pre-dinner snacking.

\section{Acknowledgements}

We acknowledge the technical staff of Optimed Clinical Research Centre (Gières, France) for carrying out the experimental work, Nicolas Démétri from Yoplait Co. for his 
assistance at every step of the study and France Bellisle for her very helpful advice in the final writing of the manuscript.

This trial was financially supported by Yoplait France.

D. C. designed and supervised the study, analysed the data and wrote the manuscript. F. P. supervised the study and reviewed the manuscript.

Conflict of interest: F. P. works for Yoplait France, the company commercialising one of the two tested food products.

\section{References}

1. Chapelot D \& Louis-Sylvestre J (2008) The role of orosensory factors in eating behavior as observed in humans. In Appetite and Food Intake: Behavioral and Physiological Considerations, pp. 133-161 [RBS Harris and RD Mattes, editors]. New York: CRC Press.

2. Kissileff HR (1985) Effects of physical state (liquid-solid) of foods on food intake: procedural and substantive contributions. Am J Clin Nutr 42, 956-965.

3. Le Magnen J \& Devos M (1984) Meal to meal energy balance in rats. Physiol Behav 32, 39-44.

4. Rogers PJ \& Blundell JE (1984) Meal patterns and food selection during the development of obesity in rats fed a cafeteria diet. Neurosci Biobehav Rev 8, 441-453.

5. Yu Y, South $\mathrm{T}$ \& Huang XF (2008) Inter-meal interval is increased in mice fed a high whey, as opposed to soy and gluten, protein diets. Appetite 5, 372-379.

6. Foltin RW \& Fischman MW (1988) The effects of varying procurement costs on food intake in baboons. Physiol Behav 43, 493-499.

7. Collier G, Johnson DF \& Mitchell C (1999) The relation between meal size and the time between meals: effects of cage complexity and food cost. Physiol Behav 67, 339-346.

8. Zorrilla EP, Inoue K, Valdez GR, et al. (2005) Leptin and postprandial satiety: acute central leptin more potently reduces meal frequency than meal size in the rat. Psychopharmacology (Berl) 177, 324-335.

9. Gatta B, Zuberbuuehler C, Arnold M, et al. (2009) Acute effects of pharmacological modifications of fatty acid metabolism on human satiety. Br J Nutr 101, 1867-1877.

10. Himaya A, Fantino M, Antoine JM, et al. (1997) Satiety power of dietary fat: a new appraisal. Am J Clin Nutr 65, 1410-1418.

11. Marmonier C, Chapelot D, Fantino M, et al. (2002) Snacks consumed in a nonhungry state have poor satiating efficiency: influence of snack composition on substrate utilization and hunger. Am J Clin Nutr 76, 518-528.

12. Melanson KJ, Westerterp-Plantenga MS, Saris WH, et al. (1999) Blood glucose patterns and appetite in time-blinded humans: carbohydrate versus fat. Am $J$ Physiol 277 , $\mathrm{R} 337-\mathrm{R} 345$.

13. Tsuchiya A, Almiron-Roig E, Lluch A, et al. (2006) Higher satiety ratings following yogurt consumption relative to fruit drink or dairy fruit drink. J Am Diet Assoc 106, 550-557.

14. Harper A, James A, Flint A, et al. (2007) Increased satiety after intake of a chocolate milk drink compared with a carbonated beverage, but no difference in subsequent ad libitum lunch intake. Br J Nutr 97, 579-583.

15. Luhovyy BL, Akhavan T \& Anderson GH (2007) Whey proteins in the regulation of food intake and satiety. $J$ Am Coll Nutr 26, 704S-712S.

16. Diepvens K, Haberer D \& Westerterp-Plantenga M (2008) Different proteins and biopeptides differently affect satiety and anorexigenic/orexigenic hormones in healthy humans. Int J Obes (Lond) 32, 510-518.
17. Isaksson $\mathrm{H}$, Sundberg $\mathrm{B}$, Aman $\mathrm{P}$, et al. (2008) Whole grain rye porridge breakfast improves satiety compared to refined wheat bread breakfast. Food Nutr Res (epublication 28 July 2008).

18. Latner JD \& Schwartz M (1999) The effects of a high-carbohydrate, high-protein or balanced lunch upon later food intake and hunger ratings. Appetite 33, 119-128.

19. Soenen S \& Westerterp-Plantenga MS (2007) No differences in satiety or energy intake after high-fructose corn syrup, sucrose, or milk preloads. Am J Clin Nutr 86, 1586-1594.

20. Veldhorst M, Smeets A, Soenen S, et al. (2008) Protein-induced satiety: effects and mechanisms of different proteins. Physiol Behav 94, 300-307.

21. Rolls BJ, Fedoroff IC, Guthrie JF, et al. (1990) Foods with different satiating effects in humans. Appetite 15, 115-126.

22. Santangelo A, Peracchi M, Conte D, et al. (1998) Physical state of meal affects gastric emptying, cholecystokinin release and satiety. Br J Nutr 80, 521-527.

23. DiMeglio DP \& Mattes RD (2000) Liquid versus solid carbohydrate: effects on food intake and body weight. Int $J$ Obes Relat Metab Disord 24, 794-800.

24. Tournier A \& Louis-Sylvestre J (1991) Effect of the physical state of a food on subsequent intake in human subjects. Appetite 16, $17-24$

25. Hulshof T, De Graaf C \& Weststrate JA (1993) The effects of preloads varying in physical state and fat content on satiety and energy intake. Appetite 21, 273-286.

26. Himaya A \& Louis-Sylvestre J (1998) The effect of soup on satiation. Appetite 30, 199-210.

27. Rothacker DQ \& Watemberg S (2004) Short-term hunger intensity changes following ingestion of a meal replacement bar for weight control. Int J Food Sci Nutr 55, 223-226.

28. Stull AJ, Apolzan JW, Thalacker-Mercer AE, et al. (2008) Liquid and solid meal replacement products differentially affect postprandial appetite and food intake in older adults. $J$ Am Diet Assoc 108, 1226-1230.

29. Mattes RD \& Rothacker D (2001) Beverage viscosity is inversely related to postprandial hunger in humans. Physiol Behav 74, 551-557.

30. Almiron-Roig E, Flores SY \& Drewnowski A (2004) No difference in satiety or in subsequent energy intakes between a beverage and a solid food. Physiol Behav 82, 671-677.

31. Tieken SM, Leidy HJ, Stull AJ, et al. (2007) Effects of solid versus liquid meal-replacement products of similar energy content on hunger, satiety, and appetite-regulating hormones in older adults. Horm Metab Res 39, 389-394.

32. Stunkard AJ \& Messick S (1985) The three-factor eating questionnaire to measure dietary restraint, disinhibition and hunger. J Psychosom Res 29, 71-83.

33. Flint A, Raben A, Blundell JE, et al. (2000) Reproducibility, power and validity of visual analogue scales in assessment of appetite sensations in single test meal studies. Int $J$ Obes Relat Metab Disord 24, 38-48.

34. Chapelot D, Marmonier C, Aubert R, et al. (2006) Consequence of omitting or adding a meal in man on body composition, food intake, and metabolism. Obesity (Silver Spring) 14, 215-227.

35. Chapelot D, Aubert R, Marmonier C, et al. (2000) An endocrine and metabolic definition of the intermeal interval in humans: evidence for a role of leptin on the prandial pattern through fatty acid disposal. Am J Clin Nutr 72, 421-431.

36. Chapelot D, Marmonier C, Aubert R, et al. (2004) A role for glucose and insulin preprandial profiles to differentiate meals and snacks. Physiol Behav 80, 721-731.

37. Chapelot D, Marmonier C, Thomas F, et al. (2000) Modalities of the food intake-reducing effect of sibutramine in humans. Physiol Behav 68, 299-308.

38. Matthews JN, Altman DG, Campbell MJ, et al. (1990) Analysis of serial measurements in medical research. BMJ 300, 230-235. 
39. Brondel L, Romer M, Van Wymelbeke V, et al. (2009) Variety enhances food intake in humans: role of sensory-specific satiety. Physiol Behav 97, 44-51.

40. Marmonier C, Chapelot D \& Louis-Sylvestre J (1999) Metabolic and behavioral consequences of a snack consumed in a satiety state. Am J Clin Nutr 70, 854-866.

41. Marmonier C, Chapelot D \& Louis-Sylvestre J (2000) Effects of macronutrient content and energy density of snacks consumed in a satiety state on the onset of the next meal. Appetite 34, $161-168$.

42. Holt SH, Miller JC, Petocz P, et al. (1995) A satiety index of common foods. Eur J Clin Nutr 49, 675-690.

43. Melanson KJ, Westerterp-Plantenga MS, Campfield LA, et al. (1999) Blood glucose and meal patterns in time-blinded males, after aspartame, carbohydrate, and fat consumption, in relation to sweetness perception. Br J Nutr 82, 437-446.

44. Stubbs RJ, Hughes DA, Johnstone AM, et al. (2000) The use of visual analogue scales to assess motivation to eat in human subjects: a review of their reliability and validity with an evaluation of new hand-held computerized systems for temporal tracking of appetite ratings. Br J Nutr 84, 405-415.

45. Drapeau V, Blundell J, Therrien F, et al. (2005) Appetite sensations as a marker of overall intake. Br J Nutr 93, 273-280.

46. Yeomans MR, Blundell JE \& Leshem M (2004) Palatability: response to nutritional need or need-free stimulation of appetite? Br J Nutr 92, Suppl. 1, S3-S14.

47. Le Magnen J, Devos M, Gaudilliere JP, et al. (1973) Role of a lipostatic mechanism in regulation by feeding of energy balance in rats. J Comp Physiol Psychol 84, 1-23.

48. Rolls BJ, Bell EA \& Thorwart ML (1999) Water incorporated into a food but not served with a food decreases energy intake in lean women. Am J Clin Nutr 70, 448-455.

49. Rolls BJ, Kim S, McNelis AL, et al. (1991) Time course of effects of preloads high in fat or carbohydrate on food intake and hunger ratings in humans. Am J Physiol 260, R756-R763. 